\title{
DESENCONTROS ENCONTRADOS: ESTUDO DO CONTO “O GRAVADOR”, DE RUBEM FONSECA, À LUZ DE TEORIAS DA FICÇÃO
}

\author{
Raquel Illescas Bueno ${ }^{1}$ \\ Fernando de Moraes Gebra²
}

\begin{abstract}
RESUMO
No curso Teoria da Fiç̧ão, da Pós-Graduação da Universidade Federal do Paraná, buscamos a aplicabilidade das teorias da ficção, analisando suas metodologias e o discurso sobre seus métodos. Propomos, aqui, uma análise de "O gravador", conto publicado no livro A coleira do cão, de 1965. Essa narrativa é exemplar da habilidade de Rubem Fonseca em montar enredos engenhosos, sem descuidar da densidade na abordagem temática. Em contos dessa natureza, a atenção do leitor naturalmente fica dividida entre o apelo da intriga, a observação da técnica pela qual o fio narrativo é estabelecido no discurso e a reflexão sobre questões importantes da vida social. Nossa proposta de análise visa a possibilitar o encontro de algumas das teorias da ficção a fim de verificar em que medida elas apresentam, com todas suas particularidades, pontos de intersecção para a análise de narrativas breves da literatura brasileira.
\end{abstract}

PALAVRAS-CHAVE: teoria da ficção; Rubem Fonseca.

\section{OS ENCONTROS COM O TEXTO}

Em meados da década de 1960, Roland Barthes, no capítulo "Introdução à análise da narrativa”, do livro Análise estrutural da narrativa: pesquisas semiológicas, revelava preocupação no tocante à busca de um método que permitisse analisar as inúmeras narrativas encontradas no mundo. O teórico francês, já nos pressupostos de sua teoria, recusou o método indutivo, pois julgava utópico o estudo de todas as narrativas de um gênero, de uma época e de uma sociedade, no intuito de um esboço geral de uma teoria da ficção. Qual seria, então, segundo os autores estruturalistas do primeiro momento, o modelo lógico e coerente de análise de textos literários, em especial de textos ficcionais?

Retomamos o próprio Barthes, cujo discurso fundador de uma teoria semiótica do discurso nos fornece elementos para a análise da estrutura imanente do texto. Essa estrutura imanente é o lugar onde se engendram significações, o que gera a necessidade de uma semiótica que dê conta dos mecanismos de produção desses diversos sentidos. Na tentativa de construir esse método, Barthes, como ficou dito, se opõe ao método indutivo, modelo utilizado nas ciências experimentais, mas que se revela ineficaz na análise literária. O método

\footnotetext{
${ }^{1}$ Raquel Illescas Bueno é doutora em Literatura Brasileira e atualmente é professora do programa de pósgraduação em Letras da Universidade Federal do Paraná.

${ }^{2}$ Fernando de Moraes Gebra é doutorando em Letras, na área de concentração Literatura Brasileira, e atualmente é professor do Centro de Línguas e Interculturalidade da Universidade Federal do Paraná.
} 
dedutivo, escolhido pelos lingüistas para descrever milhares de línguas, seria o mais apropriado, também, para a descrição das incontáveis narrativas.

O discurso fundador barthesiano e seu método dedutivo de análise de textos estão enraizados na construção de um modelo descritivo (uma teoria) para se chegar às narrativas que, ao mesmo tempo, podem participar e se afastar da teoria. Esse método foi apresentado minuciosamente e testado em algumas narrativas. Barthes parte do princípio de que, assim como a frase, o discurso possui também uma gramática, e por isso, pela análise estrutural, cada nível do discurso (assim como cada nível da frase - fonético, morfológico e sintático), é passível de uma descrição:

A teoria dos níveis (tal como enunciou Benveniste) fornece dois tipos de relações: distribucionais (se as relações estão situadas em um mesmo nível), integrativas (se elas são estabelecidas de um nível ao outro). Segue-se que as relações distribucionais não bastam para dar conta da significação. Para conduzir uma análise estrutural, é necessário pois em primeiro lugar distinguir muitas instâncias de descrição e colocar estas instâncias numa perspectiva hierárquica (integratória).(1971, p.24)

Os níveis propostos por Barthes seriam três: o das funções, o das ações e o da narração. Esses níveis apresentam correspondentes em várias teorias estruturais da narrativa, tais como a de Tzvetan Todorov, A. J. Greimas, Gérard Genette. Em As estruturas narrativas, no capítulo “Análise estrutural da narrativa”, Todorov apresenta um discurso sobre o método da análise estrutural semelhante ao de Barthes, qual seja, o conhecimento da estrutura abstrata que possibilita entender várias estruturas concretas, as narrativas (p.80). Além disso, centra sua atenção no que Barthes chama de ações, mais especificamente na estrutura do enredo, chamada por Todorov de “intriga”. Greimas também propõe, ao propor um primeiro método semiótico de análise, o exame minucioso das ações, nas relações entre sujeitos e objetos, para, posteriormente, dedicar-se ao exame das estratégias do discurso, chamado por Barthes de nível da narração.

Nossa proposta visa a possibilitar o encontro de algumas dessas teorias e verificar em que medida elas apresentam, com todas suas particularidades, pontos de intersecção para a análise de narrativas breves da literatura brasileira. No curso Teoria da Ficção, da PósGraduação da Universidade Federal do Paraná, buscamos a aplicabilidade dessas teorias, analisando constantemente suas metodologias e o discurso sobre seus métodos. Como um dos resultados desse trabalho de reflexão, surge este artigo, que busca não uma exclusão de uma teoria em relação à outra, mas sim uma complementaridade entre elas. Perguntamo-nos: essas 
teorias são válidas para a análise de contos? Seus métodos e modelos são excludentes ou complementares? Suas propostas de análise permitem uma descrição objetiva do texto narrativo, nosso objeto de estudo? Se admitirmos que as teorias sejam realmente complementares, de que maneira ocorre esse entrelaçamento?

\section{OS DESENCONTROS NO TEXTO}

“O gravador”, conto publicado no livro A coleira do cão, de 1965, é exemplar da habilidade de Rubem Fonseca em montar enredos engenhosos sem descuidar de, simultaneamente, carrear densidade ao tratamento temático. Em contos dessa natureza, a atenção do leitor naturalmente fica dividida entre o apelo da intriga, a observação da técnica pela qual o fio narrativo é estabelecido no discurso e a reflexão sobre questões importantes da vida social. Neste conto em particular, são abordadas as dificuldades de convívio social e a eutanásia, além dos conflitos próprios dos relacionamentos conjugais. Porém, uma vez que optamos por privilegiar a estrutura narrativa, a interpretação de aspectos temáticos apenas pontuará a análise, sem ser seu objetivo central. Nesse percurso, destacaremos a variedade de recursos técnicos disponibilizados pelo autor. Essa variedade convida a uma minuciosa análise imanente.

O enredo de "O gravador” pode ser assim resumido: um homem chamado Jorge Vale aproxima-se de uma mulher casada (ela se identifica primeiramente como Alice, depois como Alda) por meio de sucessivas ligações telefônicas. Ele inicialmente se apresenta como funcionário de um instituto de pesquisas, incumbido de reunir opiniões a respeito da eutanásia. Assumem importância para a ambientação os aparelhos de gravação de Jorge Vale e as observações sobre técnicas empregadas para registro de sons, incluídas as conversas telefônicas entre as personagens, que são sistematicamente gravadas e reproduzidas pelo protagonista.

Os diálogos entre Jorge e Alda são apresentados alternadamente com conversas telefônicas entre Jorge e sua mãe, que demonstra um cuidado extremo com o filho. As ofertas de auxílio da mãe são recusadas sempre em tom de grande irritação.

Os longos trechos dialogados (conversas telefônicas) alternam-se, por sua vez, com trechos narrados em primeira pessoa por Alda, contendo comentários às conversas telefônicas e desabafos sobre o descontentamento dela com seu casamento. Esses trechos evidenciam seu crescente envolvimento afetivo com Jorge Vale. Após demonstrar alguma resistência, Jorge 
aceita o convite para um primeiro encontro. Essa situação, típico anti-clímax, é assim apresentada no discurso de Alda:

Esperei duas horas, duas horas contadas no relógio e Jorge não apareceu. (...) Uma chuvinha fina caía quando cheguei, mas não podia ser esse o motivo. A chuva nem dava para molhar, havia mesmo na praça uma babá com duas crianças e um paralítico numa cadeira de rodas, sendo empurrado por seu empregado. Jorge não apareceu (2004, pp. 52-53).

Esse trecho faz perceber que ambas as personagens dirigiram-se ao local do encontro e que ela não reconheceu Jorge. Ela sequer imaginou que ele pudesse ser o "paralítico numa cadeira de rodas”. Encerrando a narrativa, Jorge telefona à mãe e pede que ela o ajude a se deitar.

É precisamente nesse anti-clímax que o leitor percebe dados do conto que estavam escondidos na estrutura narrativo-discursiva. Nesse aspecto, será válida a proposta de análise de Ricardo Piglia, que afirma que "um conto conta sempre duas histórias” (2004, p.89) e que “a história secreta é a chave da forma do conto e de suas variantes” (2004, p.91). O autor argentino retoma a teoria do iceberg, de Ernest Hemingway, de que "o mais importante nunca se conta. A história é construída com o não-dito, com o subentendido e a alusão” (2004, pp.91-2).

Nesse sentido, “O gravador” apresentaria duas histórias? Mas quais seriam essas duas histórias? Embora haja a figura da "cadeira de rodas” como elemento escondido, como o nãodito, o subentendido e a alusão, de que nos fala Hemingway, não vemos exatamente duas histórias aqui, mas sim dois planos, quais sejam, o plano do explícito (o desejo de Jorge por Alda e vice-versa), e o plano do implícito (a situação limitada de Jorge por estar preso a uma cadeira de rodas).

Duplicidade de outra natureza, perceptível visualmente (graficamente), modula o foco narrativo: aproximadamente dois terços do texto (cerca de 13 páginas, em trechos espalhados ao longo das 19 páginas do conto) correspondem ao que Norman Friedman denominou “modo dramático” de narrar. O outro terço (aproximadamente 6 páginas, divididas em 4 partes) está a cargo de Alda, e corresponde, na tipologia de Friedman, a uma das duas formas seguintes: "eu protagonista” ou “eu como testemunha”.

Considerando - como o fazemos - que é Jorge, e não Alda, o protagonista de “ $\mathrm{O}$ gravador" - teríamos, nesses trechos, a presença do "eu como testemunha”. Outra forma de analisar, ainda empregando a tipologia de Friedman, situaria Alda como "eu protagonista” no 
terço narrado por ela, o qual é alternado com trechos do “modo dramático” nos quais o protagonismo cabe a Jorge.

Tanto o “modo dramático” como as narrações em primeira pessoa favorecem o escamoteamento de informações ao longo do texto, pois resultam da progressiva diminuição da presença do narrador e do autor no texto. Lembre-se, que, para Friedman, o narrador comparece com mais intensidade nos modos denominados "autor onisciente intruso" e “narrador onisciente neutro”. Já o “modo dramático” é apresentado por Friedman como uma das categorias nas quais se observa o “desaparecimento do narrador”.

Nesse modo, o enredo avança pela justaposição de cenas, pontuadas ou não por breves anotações correspondentes àquilo que, no gênero dramático propriamente dito (peças teatrais), seriam as rubricas. Como conseqüência dessa técnica, o ângulo de visão, para o leitor, fica sendo o da "frente fixa”. É esse o efeito obtido no conto de Rubem Fonseca: temos acesso aos acontecimentos de um ângulo fixo que privilegia a casa de Jorge e, para cada conversa telefônica - típicos exemplos de “diálogo” - um tempo único, o tempo presente, que pode ser o tempo da própria conversa ou o tempo da escuta da gravação. Além das conversas, as partes apresentadas em "modo dramático" contêm: a) anotações breves que indicam ações de Jorge (“Disquei o telefone”, “Ajustei o gravador em mono”); b) anotações breves que se deduz serem pensamentos ou falas de Jorge para ele mesmo.

Friedman menciona como característica do "modo dramático" a ausência de pensamentos das personagens, porém é possível estabelecer correspondência entre os comentários/pensamentos de Jorge anotados entre parênteses e o que, no palco, seriam breves solilóquios. Esses comentários e os registros de ações intermediam as falas de Jorge com seus interlocutores sem se configurarem como fio condutor da narrativa, pois, além de serem curtos e de estarem anotados entre parênteses, são bem menos informativos do que as falas.

As falas de Jorge e Alda ou de Jorge e sua mãe estão indicadas entre aspas. Estas assumem função idêntica à dos travessões, notação mais tradicional para identificar a mudança de voz nos diálogos. Já as indicações de gestos de Jorge e seus pensamentos ou breves solilóquios estão grafados entre parênteses, em itálico, formatação usual das rubricas nos textos teatrais impressos.

Se, no “modo dramático", o narrador desapareceu, nos textos em primeira pessoa, a narrativa é limitada aos pensamentos e sentimentos de uma personagem. Independentemente de considerarmos a narração feita por Alda como exemplo do modo "eu protagonista” ou do modo "eu como testemunha", é importante constatar que nesses trechos o leitor não tem o mínimo acesso aos pensamentos de Jorge. Caso tivéssemos narrativa em primeira pessoa na 
voz de Jorge, esta, sim, seria uma narração do centro dos acontecimentos (a casa onde ficam os gravadores), e tranqüilamente a identificaríamos como exemplo do modo "eu protagonista”.

Alda revela suas emoções e dúvidas, fala sobre seu casamento e sua vida tediosa de dona de casa. Do ponto de vista espacial, ela narra da periferia, pois não freqüenta a casa de Jorge, ambiente em que se revelaria a limitação física, fosse pela visualização dos móveis e aparelhos de gravação, ou mesmo, estando ele presente, pela observação direta dele e de suas movimentações.

O conto dissemina ao longo de todo o enredo o que Roland Barthes chama de índices, isto é, uma classe integrativa de unidades narrativas, pois “as unidades que aí se encontram têm em comum o fato de não poderem ser saturadas (completadas) a não ser ao nível dos personagens ou da narração” (1971, p.32). Além disso, Barthes afirma que os índices estabelecem uma relação paramétrica, “cujo segundo termo, implícito, é contínuo, extensivo a um episódio, um personagem ou a uma obra inteira” (1971, p.32).

Tanto a proposta de Piglia como a teoria de Barthes nos fornecem elementos de análise do que chamamos de plano do implícito em “O gravador”. Em vários momentos do conto, houve rápidas alusões à situação limitada de Jorge, bem como elementos relacionados à cadeira de rodas. Esta só se constitui como índice no parágrafo acima transcrito, um dos últimos do conto. Porém, antes disso, são muitos os elementos que aludem à limitação física de Jorge Vale. Convém citarmos esses momentos da narrativa para uma apreensão da estrutura do enredo.

Os pensamentos de Jorge, transcritos entre parênteses no conto, remetem, muitas vezes a essa condição limitada. Na conversa de Jorge com um técnico de aparelhos eletrônicos, Jorge diz não poder levar o gravador até a assistência técnica. Diz e pensa: “Não posso. (Não posso. Não posso)” (p.35) três vezes repetidas. Logo em seguida, antes da primeira ligação telefônica a Alda, Jorge afirma: "Rodei pela casa em grande velocidade, sem bater num móvel sequer” (p.35).

Na segunda conversa com Alda, Jorge sente-se incomodado quando ela menciona "poder ter pena dos outros, em vez de ter pena de mim mesma” (p.43). Na transcrição do pensamento de Jorge, nos parênteses, o incômodo fica evidente, com a repetição da palavra “pena” (Pena dos outros. Pena da gente.) (p.43).

Na quarta conversa, outro momento de perturbação se dá quando Alda propõe um encontro com Jorge. Neste caso, os índices da condição limitada de Jorge aparecem nas respostas a Alda: "Sei lá, acho que saio tão pouco de casa que só em pensar nisso fico 
perturbado” (p. 50). Mais adiante, ao confirmar um local para o encontro (numa praça do centro, perto de uma estátua), Jorge alerta Alda: “Mas olha, eu não sou nada do que você está pensando, nada” (p.51).

Nos diálogos com a mãe, os índices que se relacionam a “cadeira de rodas”, ou seja, o plano do implícito, aparecem mais vezes. Na primeira conversa com a mãe, esta diz: "Logo vou aí botar você na cama”, ao que Jorge replica duas vezes: “Já disse um milhão de vezes que não precisa. Sei me deitar sozinho” (p.38).

Na segunda conversa, outra alusão à cadeira de rodas. Antes da ligação, Jorge está gravando o "Concerto das rodas sibilitantes” (p.39), algo que muito incomoda sua mãe. Jorge lhe explica que para construir músicas concretas, coloca o "microfone junto das rodas (...) enquanto elas deslizam pelo chão” (p.40). A situação de incômodo para a mãe vai aumentando até que Jorge diz: “O concerto das rodas tem que ser mau, pois a roda é má, é horrível ainda que útil, útil, útil. É escravizante. A senhora não acha que a roda é escravizante?” (p.41).

Na terceira conversa, anterior ao encontro com Alda, Jorge pede para a mãe mandar uma pessoa chamada Pedro até sua casa, enfatizando o pedido três vezes: "Mande o Pedro aqui amanhã, mamãe, bem cedo” (p.52). A mãe replica duas vezes: "Você vai sair?”, sinalizando a limitação de movimentos do filho. Essas réplicas se completam no discurso de Alda que, como já dissemos, nem percebera que era Jorge o "paralítico numa cadeira de rodas, sendo empurrado por seu empregado” (p.53), o qual seria justamente a personagem de nome "Pedro". Além disso, o conto se fecha com a quarta conversa com a mãe, em que Jorge diz: “Sim, mamãe, quero, vem me pôr para dormir” (p.53).

Retomando a análise a partir das categorias de Barthes, destaquemos que, apresentando “O gravador” em aulas de graduação e de pós-graduação em Letras - Estudos Literários, ou seja, a leitores com alto grau de especialização, o conto sempre recebeu leituras nas quais, à maneira do que acontece na narração de Alda, não houve a identificação de Jorge com o "paralítico numa cadeira de rodas". Tais leituras investiram na interpretação que privilegia as características pouco sociáveis do protagonista, atribuindo-as ora a uma relação edipiana, ora a alguma fobia social que o desmotivasse a sair de casa.

Se levamos em consideração que os índices aqui relacionados, e outros, que não mencionamos, aparecem todos ao longo de apenas 19 páginas de um conto (e não, por exemplo, disseminados ao longo de 400 páginas de algum romance), não é impressionante que muitos bons leitores não consigam fechar o círculo da interpretação a não ser numa 
segunda ou terceira leitura do conto? Atribuímos aqui essa característica à maneira como os índices e informantes estão distribuídos no texto.

Senão vejamos: os núcleos (Barthes) da ação são apenas dois, interligados. O primeiro envolve a iniciativa de Jorge de telefonar a desconhecidos para indagar sua opinião acerca da eutanásia. O segundo, resultado do primeiro, tem a ver com o envolvimento emocional entre Jorge e Alda. Suas conversas conduzem ao planejamento de um encontro, possível início de um relacionamento amoroso.

Já as conversas entre Jorge e sua mãe são catálises, ou seja, elementos menos importantes que os núcleos, mas que igualmente fazem avançar a narrativa do ponto de vista da ação, como o demonstra a penúltima conversa, acima transcrita, na qual Jorge solicita à mãe que mande Pedro a sua casa. Proporcionalmente, é grande o número de informantes (elementos secundários que carregam informação “pronta”) e de índices (elementos secundários que colaboram para o que nesta análise denominamos “plano do implícito”).

Além disso, praticamente todos os informantes atuam, noutro plano, também como índices. Um exemplo: o leitor é informado de que Jorge se julga ágil e pretende praticar basquete, mas não sabe que ele é paralítico. Os informantes “agilidade de Jorge” e “desejo de Jorge de ir à Associação e se inscrever no time de basquete” operam, num primeiro plano, como simples informações disseminadas pelo texto. Simultaneamente, podem operar como índices de sua condição limitada. Para isso, deve-se considerar que o basquete é um dos esportes mais praticados pelos cadeirantes; um dos únicos, inclusive, na época da escrita do conto (década de 60 do século 20).

Uma outra espécie de informantes é aquela que, ao contrário, não indicia nada, mas desvia a atenção do leitor, ou seja, colabora para que os demais índices sejam percebidos apenas na sua condição de informantes. Podemos nos referir a esse tipo de informante como "ruídos” do texto. Exemplo: “Record. Luz verde” (p. 37).

Em outros momentos do conto, a expressão “ruídos” não é metafórica: trata-se literalmente de ruídos com dupla (ou tripla) função no discurso. Um exemplo: observe-se a seqüência: “Click” / “Trolotrolotro-trolotro-trolotrolotro-trolotrotrolo - trolotrolotrolotrolotro. Purrr-purrr-purrr-purrr.” (p. 41) E mais esta, que passamos a analisar: "Ffuffuffuffuffufufufufufufufufufufufffffffff / Brudddd / Guhhuhuuhh / Tirrim / (Liguei o gravador que estava conectado no fio telefônico)" (pp.39-40). Antes da "rubrica” que contém uma catálise (“liguei o gravador”), o leitor é, por assim dizer, distraído com barulhos diversos, os quais podem ser lidos como sons dos aparelhos de gravação, ou, noutro plano, indiciar o deslocamento da cadeira de rodas. Os sons relacionam-se, num terceiro nível, ao convívio da 
personagem masculina com o universo da produção de música concreta. Em conversa com Alda, Jorge afirma: "Eu sou pesquisador de opinião pública. Como distração eu faço música concreta” (p. 42). Já, em conversa com a mãe, ele apresenta, quase didaticamente, diversos informantes relacionados à teoria da música concreta: "Mas a senhora não sabe quem são Schaeffer e Arthuys. Foram sujeitos que procuraram usar os ruídos como fonte de som. É o que eu faço, filtro e modulo ruídos e depois cada ruído é ordenado e justaposto (p. 41)”. Destaque-se: “filtro”, “modulo”, “ordenado”, “justaposto”.

A partir dessa seqüência, encerramos este momento de análise imanente, apontando outro caminho interpretativo possível, o de relacionar a técnica de composição da música concreta à técnica de composição do conto “O gravador”. Assim, os informantes dessa natureza não seriam apenas índices de uma atividade possível para um homem paralítico (acionar gravadores, criar música concreta), mas também índices a serviço de uma leitura metalingüística. Dito de outra forma: ao teorizar sobre a música concreta enquanto “filtragem”, “modulação”, “ordenação” e “justaposição” de ruídos, o autor nada mais fez do que "abrir sua caixa de ferramentas", indicando os procedimentos a partir dos quais ele distribuiu ruídos e falas, de maneira a escamotear o máximo possível a condição limitada de Jorge.

\section{OS ENCONTROS DAS TEORIAS}

Após descrever os processos de focalização narrativa, Friedman, nas considerações finais de seu texto, se questiona: "Mas talvez toda a questão possa ser reformulada em termos de meios e fins: o romancista utilizou as técnicas disponíveis de maneira a produzir o efeito pretendido? ou ele deixou as oportunidades escaparem e surgirem obstáculos entre o leitor e a ilusão desejada?”. Logo em seguida, conjectura: “A pressuposição básica, então, daqueles seriamente interessados pela técnica, como o próprio James apontou tempos atrás, é que a finalidade primordial da ficção é produzir a mais total ilusão possível pela estória.” E conclui, com sábia comparação: “Assim, a escolha de um ponto de vista ao se escrever ficção é, no mínimo, tão crucial quanto a escolha da forma do verso ao se compor um poema”. Comparação embasada na seguinte lógica: “A questão da eficácia, portanto, diz respeito à adequação de uma dada técnica para se conseguir certos tipos de efeitos, pois cada tipo de estória requer o estabelecimento de um tipo particular de ilusão que a sustente.”

Em “O gravador”, as técnicas narrativas empregadas, quais sejam, a presença de dois planos do discurso (o explícito e o implícito) e a simetria da focalização, ora em "modo 
dramático", ora no "eu protagonista” ou "eu como testemunha”, determinam efeitos de sentido. Vale reiterar que há no conto quatro conversas de Jorge com a mãe em "modo dramático”, quatro vezes com Alda, e quatro vezes em que o conto está no modo "eu protagonista” ou “eu como testemunha”(Alda). Algo bem simétrico, portanto, e que nos propõe um interessante jogo: ora o texto nos revela algo, ora nos oculta e nos aguça a curiosidade de buscarmos pistas, ou os índices de que nos fala Barthes, para que os significados ocultos no discurso textual se manifestem numa revelação clara para sua posterior análise.

A leitura de "O gravador", de Rubem Fonseca, ficaria limitada se apenas nos perguntássemos quais seriam as histórias explícita e implícita. Optamos por seguir a proposta de Piglia, mas sem nos atermos em história, ou em intriga, como nos propõe Todorov. Decidimos chamar as "histórias" de planos, porque o conto vai muito além da constatação de que Jorge era paraplégico. Os planos do explícito e do implícito possibilitam uma busca de índices (Barthes) disseminados ao longo do texto e que, integrados à análise das focalizações narrativas, nos permitem desvendar não apenas o plano da história, mas sim o plano do discurso, algo de relevância para os estudos literários. Não importa tanto o que se conta, mas como se conta. Os sentidos ocultos se espalham no plano do explícito, e as revelações só se mostram porque mergulhamos no oculto e lhe estabelecemos sentidos.

\section{REFERÊNCIAS}

BARTHES, Roland et. al. Análise estrutural da narrativa: pesquisas semiológicas. Petrópolis: Vozes, 1971.

FONSECA, Rubem. “O gravador”. In: A coleira do cão. 4.ed. São Paulo: Companhia das Letras, 2004.

FRIEDMAN, Norman. O ponto de vista na ficção: o desenvolvimento de um conceito crítico. Disponível em http://www.usp.br/revistausp/n53/friedman.html. Acesso em 12 ago. 2006.

PIGLIA, Ricardo. Formas breves. São Paulo: Companhia das Letras, 2004.

TODOROV, Tzvetan. As estruturas narrativas. São Paulo: Perspectiva, 1970. 